\title{
Associations between prenatal maternal exposure to per- and polyfluoroalkyl substances (PFAS) and polybrominated diphenyl ethers (PBDEs) and birth outcomes among pregnant women in San Francisco
}

Stephanie M. Eick ${ }^{1+}$, Elizabeth K. Hom Thepaksorn ${ }^{1+}$, Monika A. Izano ${ }^{1}$, Lara J. Cushing ${ }^{2}$, Yunzhu Wang ${ }^{3}$, Sabrina Crispo Smith³, Songmei Gao ${ }^{3}$, June-Soo Park ${ }^{3}$, Amy M. Padula', Erin DeMicco', Linda Valeri', Tracey J. Woodruff ${ }^{1}$ and Rachel Morello-Frosch ${ }^{1,5^{*}}$ (D)

\begin{abstract}
Background: Perfluoroalkyl substances (PFAS) and polybrominated diphenyl ethers (PBDEs) are used in consumer products for their water repellent and flame retardant properties, respectively. However, there is widespread prenatal exposure and concern about their potential harm to the developing fetus. Here, we utilized data from a demographically diverse cohort of women in San Francisco, CA to examine associations between prenatal exposure to PFAS and PBDEs with gestational age and birth weight for gestational age z-scores.

Methods: Women included in this analysis were enrolled in the Chemicals in our Bodies (CIOB) cohort study $(N=506)$. PFAS and PBDEs were measured in serum obtained during the second trimester of pregnancy. Linear regression models were used to calculate crude and adjusted $\beta$ coefficients for the association between PFAS and PBDE concentrations in tertiles and gestational age and birth weight z-scores. Individual PFAS and PBDE concentrations, as well as their sums, were examined in separate models.

(Continued on next page)
\end{abstract}

\footnotetext{
* Correspondence: rmf@berkeley.edu

†'Stephanie M. Eick and Elizabeth K. Hom Thepaksorn are co-first authors.

${ }^{1}$ Program on Reproductive Health and the Environment, Department of

Obstetrics, Gynecology and Reproductive Sciences, University of California, San Francisco, CA, USA

${ }^{5}$ Department of Environmental Science, Policy and Management and School of Public Health, University of California, Berkeley, CA, USA

Full list of author information is available at the end of the article
}

(c) The Author(s). 2020 Open Access This article is licensed under a Creative Commons Attribution 4.0 International License, which permits use, sharing, adaptation, distribution and reproduction in any medium or format, as long as you give appropriate credit to the original author(s) and the source, provide a link to the Creative Commons licence, and indicate if changes were made. The images or other third party material in this article are included in the article's Creative Commons licence, unless indicated otherwise in a credit line to the material. If material is not included in the article's Creative Commons licence and your intended use is not permitted by statutory regulation or exceeds the permitted use, you will need to obtain permission directly from the copyright holder. To view a copy of this licence, visit http://creativecommons.org/licenses/by/4.0/ The Creative Commons Public Domain Dedication waiver (http://creativecommons.org/publicdomain/zero/1.0/) applies to the data made available in this article, unless otherwise stated in a credit line to the data. 
(Continued from previous page)

Results: The highest compared to lowest tertile of BDE-47 was associated with shorter gestational age $(\beta=-0.49,95 \%$ confidence interval $[\mathrm{Cl}]=-0.95,-0.02)$. Additionally, exposure to BDE-47 and BDE-99 in the middle tertile was also associated with a reduction in birth weight z-scores $(\beta=-0.26,95 \% \mathrm{Cl}=-0.48,-0.04 ; \beta=-0.25,95 \% \mathrm{Cl}=-0.47,-0.04$, respectively) compared to those in the lowest tertile of exposure. No consistent associations were observed between increasing PFAS concentrations and gestational age or birth weight z-scores.

Discussion: Among a diverse group of pregnant women in the San Francisco Bay Area, we found non-linear associations between prenatal exposure to PBDEs during the second trimester of pregnancy and birth weight z-scores. However, most PFAS congeners were not associated with adverse birth outcomes. PFAS and PBDE concentrations were lower in our cohort relative to other studies. Future research should assess the effects of emerging and persistent PFAS and PBDEs on birth outcomes, as some congeners are being phased out and replaced by chemically similar structures.

Keywords: Per- and poly-fluroalkyl substances, Polybrominated diphenyl ethers, Birth outcomes, Health disparities

\section{Background}

Perfluoroalkyl substances (PFAS) and polybrominated diphenyl ethers (PBDEs) are persistent in the environment and ubiquitous due to their use in many consumer and industrial products. PFAS are in a wide range of products such as cookware, food containers, clothing, and fire-fighting foam due to their oil and waterrepellent properties [1]. PBDE flame retardants have been applied to items such as home furniture, electronic devices and textiles [2]. Both PFAS and PBDEs can persist in the indoor environment [3], have long elimination half-lives in the human body $[4,5]$, can bioaccumulate in animals and humans, and become magnified in the food web [6].

In humans, studies have shown that PFAS and PBDEs travel through the placenta to the fetus [7-10]. PFAS and PBDEs have also been linked to adverse birth outcomes, including preterm birth (PTB) and low birth weight $(\mathrm{LBW})$. For example, a recent systematic review of the effects of PFOA on fetal growth found that a 1 $\mathrm{ng} / \mathrm{mL}$ increase in serum or plasma PFOA was associated with a $-18.9 \mathrm{~g}$ ( $95 \%$ confidence interval $[\mathrm{CI}]=-$ 29.8, - 7.9) decrease in birth weight [11]. Elevated levels of PFOA have also been associated with an increased risk of PTB [12]. In addition to PFOA, PFOS concentrations have been linked to a reduction in birth weight, gestational age and increased odds of PTB [12-14]. Despite the consistency for PFOA and PFOS, evidence for other PFAS has been mixed. Some studies suggest that higher concentrations of PFHxS [15] and PFNA [16] are associated with lower birth weight, while other studies have found null associations [14, 17]. The relationships between PFNA, gestational age, and PTB have also been inconsistent $[13,14]$.

Studies on the effects of PBDEs on birth outcomes are also mixed. In a recent meta-analysis, a one log unit increase in exposure to multiple PBDEs (BDE-47, BDE-99, BDE-100 and BDE-153) was associated with a-50.6 g decrease in birth weight $(95 \% \mathrm{CI}=-95.9,-5.3)$ [18].
However, effect estimates are highly variable across individual studies [19-21]. Similar inconsistencies have been observed with gestational age. For example, two studies found no association between maternal serum concentrations of BDE-47 and BDE-99 and gestational age [20, $21]$, while another study found that elevated maternal serum concentrations of BDE-47 were associated with increased odds of PTB [22].

In response to health concerns, the US EPA worked with industry for a voluntary phase out of new production and import of PFOA in 2006 [23], PFOS by 3M in 2000-2002, and PentaBDE (which includes BDE-47 and BDE-99) [24]. California banned PBDEs in 2006, partially in response to studies showing that Californians had higher levels of PBDEs compared to other areas in the U.S. and globally [25-27]. This is likely due to the state's strict flammability standard, which was revised in 2013 to improve fire safety without the use of flame retardant chemicals [28]. Since implementation of these regulatory reforms, blood serum concentrations of certain PBDEs and PFAS have subsequently declined [29-31]. However, while levels may have dropped, both PFAS and PBDEs remain ubiquitously present in the serum of pregnant women, and levels of certain chemicals, such as PFHxS [31] and PFNA [32], are not declining; a study of 65 pregnant women in the San Francisco Bay Area found that PFAS and PBDEs were detected in 98-100\% and 56-90\% of the maternal and cord blood samples, respectively [33]. A second study of pregnant women in California found that serum levels of BDE-47 and BDE-99 decreased from 2008 to 2011 and then plateaued from 2011 to 2014 [34].

To date, most studies have focused on specific PFAS and PBDE congeners, such as PFOA, PFOS, BDE-47, and BDE-99. However, there are continued widespread exposures to these persistent chemicals and newer chemicals are constantly being introduced to the market. Thus, there is uncertainty about the relationship between prenatal exposure to certain PFAS and PBDEs 
and adverse pregnancy outcomes. Therefore, the goal of this study was to characterize the association between prenatal exposure to PFAS and PBDEs and adverse birth outcomes. We included a number of PFAS and PBDE congeners not previously explored in this context, and hypothesized that higher maternal exposure to PFAS and PBDEs during pregnancy would be associated with a reduction in gestational age and birth weight z-scores.

\section{Methods}

\section{Study population}

Women included in the analysis were enrolled in the Chemicals in our Bodies (CIOB) study, a prospective birth cohort examining the effects of chemical and chronic psychosocial stress during pregnancy. All participants were recruited between 2014 and 2018 from prenatal clinics at the Zuckerberg San Francisco General Hospital (ZSFG) or Mission Bay (MB)/Moffitt Long (ML) hospitals during their 2nd trimester of pregnancy (between 12 and 28 weeks of gestation). Participants recruited from ZSFG were predominantly lower income women of color without private health insurance, whereas participants recruited from $\mathrm{MB} / \mathrm{ML}$ were economically and racially/ethnically diverse and included women of higher socioeconomic status.

Women were eligible for inclusion in $\mathrm{CIOB}$ if they were older than 18 years of age, did not have a diagnosed pregnancy complication, were English or Spanish speaking, expecting a singleton birth, and planned to deliver at ZSFG or MB/ML. CIOB study protocols were approved by the Institutional Review Boards of the University of California, San Francisco (10-00861) and Berkeley (201005-04). All women provided written, informed consent prior to participating in the study. Further information describing recruitment methods for CIOB is available elsewhere [33].

\section{Covariates}

Demographic information was collected via standardized questionnaire following informed consent and included: maternal age, maternal race/ethnicity (non-Hispanic $[\mathrm{NH}]$ White, NH Black, Hispanic, NH Asian), prepregnancy body mass index (BMI; $<18.5 \mathrm{~kg} / \mathrm{m}^{2}, 18.5-24.9$ $\left.\mathrm{kg} / \mathrm{m}^{2}, 25-29.9 \mathrm{~kg} / \mathrm{m}^{2}, \geq 30 \mathrm{~kg} / \mathrm{m}^{2}\right)$, maternal education (< high school, high school completion or some college, college degree, >college degree or graduate education), parity (no prior births, one or more prior births), smoking status (never, ever, current), and country of birth (U.S., Other).

We additionally assessed food insecurity, as certain foods, food packaging, and reliance on food banks, have been associated with higher PFAS levels [35, 36]. Furthermore, food insecurity has been associated with adverse birth outcomes independent of pre-pregnancy BMI [37, 38]. This was done by asking participants five questions [39]. First, participants were asked how often within the last 12 months they (1) did not have enough money to purchase food or (2) could not afford to eat balanced and nutritious meals. Participants were additionally asked if, within the last 12 months, the following events ever occurred as a result of not having enough money to purchase food: (3) participants cut meals because there was not enough money for food, (4) participants ate less than they should, or (5) participants were hungry but chose not to eat. Women were considered food insecure if they reported yes to any of these events occurring.

\section{PFAS and PBDE exposure}

Maternal whole blood was collected between 12 and 28 weeks gestation in red top tubes. Serum samples were centrifuged and aliquoted prior to storage at $-80^{\circ} \mathrm{C}$ until analysis for 31 analytes (12 PFAS and 19 PBDEs). Analyses were performed by the Environmental Chemical Laboratory at the California Department of Toxic Substances Control (DTSC). Method detection limits (MDL) were calculated as 3 times the standard deviation of the blank concentrations for all PFAS and PBDEs [33]. Quality assurance plans were required for this study and were reviewed annually.

Serum preparation and extraction procedures were completed in the laboratory of DTSC. Briefly, serum was thawed, spiked with surrogate standards, denatured, and ran on an automated Biotage rapid trace SPE Work Station. Extractions were concentrated, cleaned up with acidic silica gel, reconcentrated, combined with internal standards, and analyzed for PBDEs by gas chromatography/high resolution mass spectrometry (GC-HRMS, DFS, Thermo-Scientific, Bremen, Germany) using isotope dilution [40]. PFAS were quantified by injection onto an automated on-line solid phase extraction method coupled to liquid chromatography and tandem mass spectrometry. Lipid content in maternal serum was also measured. Biospecimen collection instruments were chosen based on contamination testing results and instruments were tested for contamination prior to analyses. If contamination was found, other biospecimen collection and storage methods and instruments were used. Additional details regarding PFAS and PBDE measurement is provided elsewhere [33]. Values below the MDL were assigned the machine read value if a signal was detected. Chemicals that were below the MDL and no signal was obtained were coded as missing.

All wet-weight PBDE congeners were adjusted with lipid serum concentrations. For consistency with previous research, we included PFAS and PBDE congeners with $\geq 80 \%$ of samples above the MDL in our statistical analysis [41]. Based on this detection frequency cut-off, we examined associations between 5 PFAS (PFNA, 
PFOS, PFOA, Me-PFOSA-AcOH, and PFHxS) and 2 PBDEs (BDE-47 and BDE99) congeners in relation to birth outcomes. For these compounds, measurements below the MDL were assigned the machine-read value if a signal was detected. If a signal was not detected and the concentration was below the MDL, measurements were treated as missing.

\section{Birth outcomes}

Participants' medicals records were abstracted by trained study staff for the following measures: final gestational age at delivery in weeks, birth weight in grams, infant length, and infant head circumference. Gestational age on the medical record was calculated based on bestestimated date of delivery. If gestational age was missing on the medical record, it was imputed by subtracting date of last menstrual period from date of birth when this information was available $(N=6)$. Birth weight for gestational age z-scores were calculated using a U.S. population reference [42]. Birth weight z-scores are preferred over birth weight, as they account for gestational age at delivery and disentangle the effects of gestational age versus fetal growth.

\section{Statistical analysis}

We computed descriptive statistics for all demographic characteristics, birth outcomes, and PFAS and PBDE concentrations within our study population. Spearman correlation coefficients were calculated to assess the relationships between log-transformed PFAS and PBDE concentrations.

We used linear regression models to calculate crude and adjusted $\beta$ estimates and 95\% CIs for the associations between tertiles of individual PFAS and PBDE congeners and gestational age and birth weight z-scores. We examined associations between tertiles of PFAS and PBDE concentrations and PTB using logistic regression. We also included the sum of 5 PFAS and 2 PBDE congeners (the PFAS and PBDEs with a minimum $80 \%$ detection frequency) as exposures in separate models. All demographic characteristics were explored as potential covariates in adjusted analyses. Covariates retained in final adjusted models were associated with birth weight or gestational age in bivariate analyses at $p<0.10$ and had empirical evidence in the literature supporting an association with both the exposure and outcome. Final models were adjusted for maternal age, race/ethnicity, pre-pregnancy BMI, education, smoking status, parity, and food insecurity.

We conducted a number of sensitivity analyses to examine the robustness of our findings, and present the results in the supplemental information. First, we used linear regression to examine associations between tertiles of PFAS and PBDE concentrations with continuous birth weight restricted to term births only. We restricted our analysis to term births as birth weight is often confounded by gestational age. Second, we explored infant sex differences by examining the association between tertiles of individual PFAS and PBDE congeners and gestational age and birth weight $\mathrm{z}$-scores stratified by infant sex, as prior research has shown sex-specific effects of endocrine disrupting chemicals. Lastly, we examined wet-weight PBDE concentrations with lipids as a covariate in relation to gestational age and birth weight zscores.

All analyses were conducted in R Version 3.6.0. In all regression models, missing data for birth outcomes, covariates, and tertiles of PFAS and PBDE concentrations was handled using Multiple Imputation via Chained Equations (mice). Measurements that were below the MDL and did not have a machine read value $(<1 \%$ of measurements) were treated as missing. Using the mice approach, the variables with complete data are used to predict the missing values. We used the 'mice' package [43] to produce 10 datasets with complete information and these datasets were pooled in subsequent analyses.

\section{Results}

There were 510 pregnant women enrolled in the CIOB study. Of this group, 4 participants withdrew prior to delivery, leaving a sample size of 506 for our analysis. The majority of women self-identified as Non-Hispanic (NH) White (38.6\%) or Hispanic (34\%), and over half of our analytic sample was between 25 and 34 years of age (Table 1). Approximately half of our study population had a normal pre-pregnancy BMI (47.6\%) and one or more prior births $(50 \%)$. Most women had a college degree $(22.9 \%)$ or graduate education (37.5\%). Distribution of demographic characteristics stratified by study hospital is provided in Table S1.

The geometric mean of PFAS and PBDEs varied across compounds. The highest median observed was for BDE47 and BDE-99 (median = $10.9 \mathrm{ng} /$ gram lipid and $4.1 \mathrm{ng} /$ gram lipid, respectively). Among the PFAS, PFOS had the highest median $(1.93 \mathrm{ng} / \mathrm{mL})$ followed by PFOA $(0.76 \mathrm{ng} / \mathrm{mL})$ (Table 2). BDE-99 and BDE-47 were highly correlated (Spearman's $\mathrm{R}=0.89$; $p$-value $<0.01$ ). PFAS concentrations were also moderately correlated with one another (Spearman's $\mathrm{R}=0.14$ to $0.74 ; p$ value $<0.05$ for each correlation) but not with PBDEs (Table 3).

In adjusted models, the highest compared to the lowest tertiles of PFOA, PFOS, PFNA, and total PFAS concentrations were moderately associated with a reduction in gestational age, although the confidence intervals included the null value (Table 4). The upper two tertiles of PFHxS concentrations were associated with an increase in gestational age relative to the lowest tertile $(\beta=0.42$, $95 \% \quad \mathrm{CI}=0.00, \quad 0.85 ; \quad \beta=0.48, \quad 95 \% \quad \mathrm{CI}=0.03, \quad 0.92$, 
Table 1 Demographic characteristics of Chemicals in Our Body (CIOB) study population $(N=506)$

\begin{tabular}{|c|c|}
\hline & $\mathrm{N}(\%)$ \\
\hline \multicolumn{2}{|l|}{ Maternal Age } \\
\hline Mean (SD) & $32(5.4)$ \\
\hline \multicolumn{2}{|l|}{ Maternal Race/Ethnicity } \\
\hline Non-Hispanic White & $193(38 \%)$ \\
\hline Non-Hispanic Black & $40(8 \%)$ \\
\hline Hispanic & $173(34 \%)$ \\
\hline Asian/Pacific Islander & $95(19 \%)$ \\
\hline Missing & $5(1 \%)$ \\
\hline \multicolumn{2}{|l|}{ Pre-pregnancy Body Mass Index } \\
\hline Underweight $\left(<18.5 \mathrm{~kg} / \mathrm{m}^{2}\right)$ & $12(2 \%)$ \\
\hline Normal $\left(18.5-24.9 \mathrm{~kg} / \mathrm{m}^{2}\right)$ & $236(47 \%)$ \\
\hline Overweight $\left(25-29.9 \mathrm{~kg} / \mathrm{m}^{2}\right)$ & $128(25 \%)$ \\
\hline Obese $\left(\geq 30 \mathrm{~kg} / \mathrm{m}^{2}\right.$ ) & $89(18 \%)$ \\
\hline Missing & $41(8 \%)$ \\
\hline \multicolumn{2}{|l|}{ Infant Sex } \\
\hline Female & $257(51 \%)$ \\
\hline Missing & $27(5.3 \%)$ \\
\hline \multicolumn{2}{|l|}{ Parity } \\
\hline One or More Previous Births & $254(50 \%)$ \\
\hline Missing & $7(1 \%)$ \\
\hline \multicolumn{2}{|l|}{ Maternal Education } \\
\hline$<$ High School & $59(12 \%)$ \\
\hline High School Graduate or Some College & $139(27 \%)$ \\
\hline College Degree & $116(23 \%)$ \\
\hline Graduate Level Degree & $185(37 \%)$ \\
\hline Missing & $7(1 \%)$ \\
\hline \multicolumn{2}{|l|}{ Smoking Status } \\
\hline Never & $421(83 \%)$ \\
\hline Ever & $60(12 \%)$ \\
\hline Current & $10(2 \%)$ \\
\hline Missing & $15(3 \%)$ \\
\hline \multicolumn{2}{|l|}{ Difficulty Paying for Basics } \\
\hline Yes & $146(29 \%)$ \\
\hline Missing & $12(2 \%)$ \\
\hline \multicolumn{2}{|l|}{ Food Insecurity } \\
\hline Yes & $79(16 \%)$ \\
\hline \multicolumn{2}{|l|}{ Foreign Born } \\
\hline Yes & $209(41 \%)$ \\
\hline Missing & $75(15 \%)$ \\
\hline \multicolumn{2}{|l|}{ Preterm Birth } \\
\hline$<37$ weeks gestation & $41(8 \%)$ \\
\hline Missing & $13(3 \%)$ \\
\hline
\end{tabular}

Table 1 Demographic characteristics of Chemicals in Our Body (CIOB) study population $(N=506)$ (Continued)

\begin{tabular}{ll}
\hline & Median (SD) \\
Birth Weight (grams) & $3300(580)$ \\
Missing & $18(4 \%)$ \\
Gestational Age at Delivery (weeks) & $39(2.0)$ \\
Missing & $13(3 \%)$ \\
\hline Note: percentages may not sum to 100 due to rounding
\end{tabular}

Abbreviations: $S D$ standard deviation

respectively) in unadjusted models (Table S2). These associations were attenuated in adjusted models (Table 4). Increasing concentrations of BDE-47, BDE-99, and total PBDE were associated with reduced gestational age in crude models (Table S2). After adjustment, associations between BDE-47 and gestational age persisted, where the highest compared to lowest tertile of BDE-47 was associated with a 0.49 week decrease in gestational age $(95 \% \mathrm{CI}=-0.95,-0.02)$ (Table 4$)$.

Me-PFOSA-AcOH was associated with a reduction in birth weight $\mathrm{z}$-scores $(\beta=-0.24,95 \% \mathrm{CI}=-0.46,-0.02$ for the middle compared to lowest tertile). No associations were observed between other PFAS congeners (PFOA, PFOS, PFHxS, total PFAS) and birth weight zscores (Table 4). Compared to those in the lowest tertile, individuals in the middle tertile of BDE-47, BDE-99, and total PBDE concentrations had reduced birth weight $\mathrm{z}$ scores with a reduction of $-0.26(95 \% \mathrm{CI}=-0.48$, $0.04),-0.25(95 \% \mathrm{CI}=-0.47,-0.04)$, and $-0.26(95 \%$ $\mathrm{CI}=-0.48,-0.04)$, respectively (Table 4$)$. Associations were similar in unadjusted models (Table S3).

Logistic regression models indicated that increasing tertiles of PFAS and PBDE concentrations were associated with a moderate, non-significant, increase in odds of PTB across all congeners examined (Table 5). The highest compared to lowest tertile of BDE- 47 and total PBDE were associated with increased odds of PTB in unadjusted models $(\mathrm{OR}=2.88,95 \% \mathrm{CI}=1.27,6.51 ; \mathrm{OR}=$ $2.42,95 \% \mathrm{CI}=1.09,5.40$, respectively) (Table S4). OR estimates were attenuated in adjusted models (Table 5).

Results from models using wet-weight measurements of PBDEs, controlling for lipid levels, in relation to gestational age and birth weight $\mathrm{z}$-scores were similar to models using lipid-adjusted PBDE measures (Table S5-S6). When term birth weight was the outcome of interest, no clear patterns emerged in relation to increasing PFAS concentrations. However, the middle compared to lowest tertile of BDE-47 was associated with a 100.85 gram reduction in term birth weight $(95 \% \mathrm{CI}=-200.56,-1.11)$ after adjusting for confounders (Table $\mathrm{S7}$ ). When stratifying by infant sex, the association between BDE-47 and a reduction in birth weight $\mathrm{z}$-scores was stronger among females as compared to males (Table S8). No clear sex differences were observed when 
Table 2 Distributions of PFAS ( $\mathrm{ng} / \mathrm{mL}$ ) and PBDE (ng/g lipid) concentrations in maternal serum

\begin{tabular}{|c|c|c|c|c|c|c|c|c|}
\hline & & $\begin{array}{l}\mathrm{MDL} \\
(\mathrm{ng} / \mathrm{mL})\end{array}$ & $\begin{array}{l}\text { \% Above } \\
\text { MDL }\end{array}$ & $\begin{array}{l}\text { \% Machine } \\
\text { Readable }\end{array}$ & Median & $\begin{array}{l}\text { IQR (25th } \\
\text { Percentile, } \\
\text { 75th Percentile) }\end{array}$ & $\begin{array}{l}\text { 95th } \\
\text { Percentile }\end{array}$ & Maximum \\
\hline \multicolumn{9}{|l|}{ PFAS } \\
\hline Perfluorononanoic Acid & PFNA & 0.06 & 98.8 & 99.6 & 0.30 & $(0.20,0.44)$ & 0.85 & 18.7 \\
\hline Perflucorooctane Sulfonic Acid & PFOS & 0.07 & 100.0 & 100.0 & 1.93 & $(1.18,3.13)$ & 6.06 & 14.5 \\
\hline Perfluorooctanoic Acid & PFOA & 0.13 & 99.8 & 100.0 & 0.76 & $(0.46,1.12)$ & 2.11 & 32.2 \\
\hline $\begin{array}{l}\text { Methyl-perfluorooctane sulfonamide } \\
\text { Acetic Acid }\end{array}$ & Me-PFOSA-AcOH & 0.01 & 98.8 & 99.8 & 0.05 & $(0.03,0.08)$ & 0.19 & 1.79 \\
\hline Perfluorohexanesulphonic Acid & PFHXS & 0.01 & 100.0 & 100.0 & 0.33 & $(0.20,0.59)$ & 1.52 & 4.94 \\
\hline Total PFAS > 80\% MDL & & & & & 3.68 & $(2.30,5.72)$ & 10.2 & 54.7 \\
\hline Perfluorodecanoic Acid & PFDeA & 0.08 & 69.2 & 92.3 & 0.16 & $(0.12,0.24)$ & 0.50 & 3.87 \\
\hline Perfluoroundecanoic Acid & PFUdA & 0.05 & 71.9 & 95.3 & 0.14 & $(0.09,0.23)$ & 0.40 & 1.26 \\
\hline Perfluorooctane Sulfonamide & PFOSA & 0.02 & 2.37 & 42.5 & $<\mathrm{MDL}$ & $(<\mathrm{MDL},<\mathrm{MDL})$ & $<\mathrm{MDL}$ & 0.11 \\
\hline Perfluorobutane Sulfonate & PFBS & 0.03 & 0.79 & 52.0 & $<\mathrm{MDL}$ & $(<\mathrm{MDL},<\mathrm{MDL})$ & $<\mathrm{MDL}$ & 0.10 \\
\hline Perfluoroheptanoic Acid & PFHpA & 0.05 & 12.1 & 67.2 & $<\mathrm{MDL}$ & $(<\mathrm{MDL},<\mathrm{MDL})$ & 0.17 & 0.49 \\
\hline Perfluorododecanoic Acid & PFDoA & 0.20 & 2.17 & 57.9 & $<M D L$ & $(<\mathrm{MDL},<\mathrm{MDL})$ & $<M D L$ & 0.48 \\
\hline $\begin{array}{l}\text { Ethyl-perfluorooctane sulfonamido } \\
\text { Acetic Acid }\end{array}$ & Et-PFOSA-AcOH & 0.01 & 10.5 & 66.2 & $<\mathrm{MDL}$ & $(<\mathrm{MDL},<\mathrm{MDL})$ & 0.05 & 0.09 \\
\hline \multicolumn{9}{|l|}{ PBDE } \\
\hline 2,2',4,4'-tetra-bromodiphenyl ether & BDE-47 & 0.02 & 99.8 & 100.0 & 10.9 & $(7.32,17.0)$ & 39.7 & 364.3 \\
\hline $2,2^{\prime}, 4,4^{\prime}, 5$-penta-bromodiphenyl ether & BDE-99 & 0.02 & 84.4 & 99.0 & 4.1 & $(2.95,5.91)$ & 11.9 & 141.3 \\
\hline Total PBDE $>80 \% \mathrm{MDL}$ & & & & & 16.2 & $(11.9,25.6)$ & 54.2 & 505.6 \\
\hline 2,2',4'-tri-bromodiphenyl ether & BDE-17 & 0.02 & 0.00 & 14.4 & $<\mathrm{MDL}$ & $(<\mathrm{MDL},<\mathrm{MDL})$ & $<\mathrm{MDL}$ & $<\mathrm{MDL}$ \\
\hline 2,4,4'-tri-bromodiphenyl ether & $\mathrm{BDE}-28$ & 0.02 & 5.34 & 64.0 & $<\mathrm{MDL}$ & $(<\mathrm{MDL},<\mathrm{MDL})$ & 9.00 & 15.9 \\
\hline 2,3',4,4'-tetra-bromodiphenyl ether & BDE-66 & 0.02 & 0.20 & 9.88 & $<\mathrm{MDL}$ & $(<\mathrm{MDL},<\mathrm{MDL})$ & 4.10 & 4.10 \\
\hline $2,2^{\prime}, 3,4,4^{\prime}$-penta-bromodiphenyl ether & BDE-85 & 0.02 & 0.99 & 11.7 & $<\mathrm{MDL}$ & $(<\mathrm{MDL},<\mathrm{MDL})$ & $<\mathrm{MDL}$ & 12.6 \\
\hline 2,2',4,4',6-penta-bromodiphenyl ether & BDE-100 & 0.03 & 44.5 & 100.0 & $<\mathrm{MDL}$ & $(<\mathrm{MDL}, 16.1)$ & 16.1 & 90.2 \\
\hline $2,2^{\prime}, 4,4^{\prime}, 5,5^{\prime}$-hexa-bromodiphenyl ether & BDE-153 & 0.03 & 57.9 & 95.1 & 9.59 & $(<M D L, 44.2)$ & 44.2 & 232.1 \\
\hline $2,2^{\prime}, 4,4^{\prime}, 5,6^{\prime}$-hexa-bromodiphenyl ether & BDE-154 & 0.03 & 0.79 & 14.0 & $<\mathrm{MDL}$ & $(<\mathrm{MDL},<\mathrm{MDL})$ & $<\mathrm{MDL}$ & 15.9 \\
\hline $2,2^{\prime}, 3,4,4^{\prime}, 5^{\prime}, 6$-hepta-bromodiphenyl ether & BDE-183 & 0.03 & 0.20 & 20.2 & $<M D L$ & $(<M D L,<M D L)$ & $<M D L$ & 4.17 \\
\hline $2,2^{\prime}, 3,3^{\prime}, 4,4^{\prime}, 5,6^{\prime}$-octa-bromodiphenyl ether & BDE-196 & 0.03 & 0.00 & 15.8 & $<\mathrm{MDL}$ & $(<\mathrm{MDL},<\mathrm{MDL})$ & $<\mathrm{MDL}$ & $<M D L$ \\
\hline $2,2^{\prime}, 3,3^{\prime}, 4,4^{\prime}, 6,6^{\prime}$-octa-bromodiphenyl ether & BDE-197 & 0.03 & 0.99 & 43.9 & $<\mathrm{MDL}$ & $(<\mathrm{MDL},<\mathrm{MDL})$ & $<\mathrm{MDL}$ & 23.6 \\
\hline $2,2^{\prime}, 3,3^{\prime}, 4,5^{\prime}, 6,6^{\prime}$-octa-bromodiphenyl ether & BDE-201 & 0.03 & 0.00 & 16.8 & $<\mathrm{MDL}$ & $(<\mathrm{MDL},<\mathrm{MDL})$ & $<\mathrm{MDL}$ & $<M D L$ \\
\hline $2,2^{\prime}, 3,3^{\prime}, 5,5^{\prime}, 6,6^{\prime}$-octa-bromodiphenyl ether & BDE-202 & 0.03 & 0.00 & 12.7 & $<\mathrm{MDL}$ & $(<\mathrm{MDL},<\mathrm{MDL})$ & $<\mathrm{MDL}$ & $<M D L$ \\
\hline $2,2^{\prime}, 3,4,4^{\prime}, 5,5^{\prime}, 6$-octa-bromodiphenyl ether & BDE-203 & 0.03 & 0.00 & 13.0 & $<\mathrm{MDL}$ & $(<\mathrm{MDL},<\mathrm{MDL})$ & $<\mathrm{MDL}$ & $<\mathrm{MDL}$ \\
\hline $2,2^{\prime}, 3,3^{\prime}, 4,4^{\prime}, 5,5^{\prime}, 6$-nona-bromodiphenyl ether & BDE-206 & 0.04 & 0.00 & 15.8 & $<\mathrm{MDL}$ & $(<\mathrm{MDL},<\mathrm{MDL})$ & $<\mathrm{MDL}$ & $<\mathrm{MDL}$ \\
\hline $2,2^{\prime}, 3,33^{\prime}, 4,4^{\prime}, 5,6,6^{\prime}$-nona-bromodiphenyl ether & BDE-207 & 0.04 & 0.79 & 53.6 & $<\mathrm{MDL}$ & $(<\mathrm{MDL},<\mathrm{MDL})$ & $<\mathrm{MDL}$ & 13.1 \\
\hline 2,2',3,3',4,5,5',6,6'-nona-bromodiphenyl ether & BDE-208 & 0.04 & 0.00 & 27.5 & $<\mathrm{MDL}$ & $(<\mathrm{MDL},<\mathrm{MDL})$ & $<\mathrm{MDL}$ & $<\mathrm{MDL}$ \\
\hline 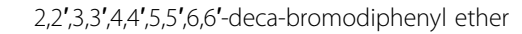 & BDE-209 & 0.14 & 2.77 & 58.1 & $<M D L$ & $(<M D L,<M D L)$ & $<M D L$ & 75.5 \\
\hline
\end{tabular}

Abbreviations: PFAS per- and polyfluoroalkyl substances, $P B D E$ polybrominated diphenyl ethers, $M D L$ method detection limit, IQR interquartile range Note: \% machine readable indicates the percent of PFAS and PBDE concentrations in which a signal was obtained. Median, IQR, 95th Percentile, and Maximum values were calculated with PFAS and PBDE concentrations below the MDL coded as missing

PFAS and PBDE congeners were modeled in relation to gestational age (Table S9).

\section{Discussion}

In a demographically diverse cohort of pregnant women in San Francisco, California, we observed that women with elevated levels of BDE-47 and BDE-99 had shortened gestational age and a reduction in birth weight z-scores. We did not observe consistent associations between PFAS concentrations and gestational age or birth weight for gestational age z-scores. In our cohort, PFAS and PBDE concentrations were lower relative to other studies $[12,13,34,44]$. 
Table 3 Spearman correlation coefficients and corresponding $p$-values for natural log transformed PFAS $(\mathrm{ng} / \mathrm{mL})$ and lipidadjusted PBDE ( $\mathrm{ng} / \mathrm{g}$ lipid) concentrations with $>80 \%$ detection in maternal serum $(N=506)$

\begin{tabular}{|c|c|c|c|c|c|c|c|}
\hline & PFNA & PFOS & PFOA & $\begin{array}{l}\text { Me- } \\
\text { PFOSA- } \\
\text { AcOH }\end{array}$ & PFHxS & BDE-47 & BDE-99 \\
\hline \multicolumn{8}{|l|}{ PFNA } \\
\hline PFOS & $0.71^{* *}$ & & & & & & \\
\hline PFOA & $0.74^{* *}$ & $0.60^{* *}$ & & & & & \\
\hline $\begin{array}{l}\text { Me- } \\
\text { PFOSA- } \\
\text { AcOH }\end{array}$ & $0.16^{* *}$ & $0.24^{* *}$ & $0.14^{* *}$ & & & & \\
\hline PFHXS & $0.56^{* *}$ & $0.67^{* *}$ & $0.69^{* *}$ & $0.16^{* *}$ & & & \\
\hline BDE-47 & -0.06 & $-0.08^{*}$ & -0.06 & $0.16^{* *}$ & -0.06 & & \\
\hline BDE-99 & -0.06 & $-0.08^{*}$ & -0.06 & 0.10 & $-0.08^{*}$ & $0.89^{* *}$ & \\
\hline
\end{tabular}

*Indicates $p<0.10$

${ }^{*}$ Indicates $p<0.05$

The inverse association between gestational age and prenatal exposure to BDE-47 in the highest compared to lowest tertile is consistent with prior research. For example, a study in Texas found that women in the upper two quartiles of BDE-47 had increased odds of PTB [22]. In contrast, neither the CHAMACOS cohort in Salinas Valley nor a prospective birth cohort in China found associations between PBDE exposure and reduced gestational age $[19,21]$. In our study, we observed no association between gestational age and BDE-99 or BDE-47 in the middle versus lowest tertile, which may suggest that levels of PBDE exposure higher than what we observed in our study are needed to observe gestational age effects. Additionally, our study found that exposure to BDE-47 and BDE-99 in the middle, but not the upper, tertile was associated with a reduction in birth weight $\mathrm{z}$-scores, which suggests that the association between PBDEs and birth weight may not be linear. This supports previous findings which also reported non-linear associations between PBDE exposure and birth weight [21].

We observed no clear associations between PFAS, gestational age, and birth weight $\mathrm{z}$-scores. Other studies have also observed inconsistent associations between exposure to certain PFAS congeners and continuous measures of gestational age or birth weight $[14,17,45]$. However, our analysis indicated that women in the upper two tertiles of PFOA, PFOS, PFHxS, and PFNA had moderately, albeit non-significant, increased odds of PTB relative to women in the lowest tertile. These findings align with those observed in the Project Viva cohort in Eastern Massachusetts, where women in the upper two quartiles of PFOS, PFNA, and PFHxS had slightly increased odds of PTB compared to the referent group [13]. Similarly, increasing exposure to PFOA and PFOS was associated with increased odds of PTB among 3535 women in Denmark [12].
Discrepancies across studies may be due to differences in the timing during pregnancy when PFAS is measured, as studies assessing temporal trends in PFAS levels during pregnancy have shown that levels tend to decrease with increasing gestational age [46]. Inconsistences between studies may also be due to temporal and geographic variability in PFAS levels, as well as phase-outs in the use, import and manufacturing of some PFAS in the U.S. and elsewhere [47]. Temporal exposure studies in the U.S. have shown that levels of some PFAS have been decreasing $[31,48]$. Although use of several PFAS and PBDE compounds in our study have declined, many are persistent and bioaccumulative, and their presence in durable consumer products, such as furniture, building materials and flooring suggests that exposures are likely to last several decades [49]. In addition, PFAS and PBDE substitutes, such as GenX and PFBS, have not been well studied and are suspected to have similar harmful health effects as the chemicals they were designed to replace [50]. Future studies should characterize prenatal exposures and birth outcome effects of these substituted chemicals currently being used to achieve similar water and oil repellent properties and flame retardant features of phased out PFAS and PBDEs.

PFAS and PBDEs may be affecting fetal growth through several mechanisms. One hypothesis is that PFAS disrupt estrogen and thyroid hormones. Both estrogen and thyroid hormones are important for normal fetal growth and development, and maternal hypothyroidism has been associated with lower birth weight $[51,52]$. Human in vitro studies have shown that PFAS, such as PFOS and PFOA, interfere with estrogen receptors [53-55]. Animal studies have also shown that PFAS disrupt normal thyroid function [56] and biosynthesis of thyroid and reproductive hormones $[55,57]$. Another possible mechanism may be elevated oxidative stress, which has been associated with increased odds of PTB [58] and is hypothesized to be a downstream consequence of PFAS exposure [59]. PBDEs may affect birth outcomes through disruption of thyroid function. The thyroid hormone influences fetal growth and development throughout gestation. For example, during fetal development, the thyroid hormone stimulates intrauterine growth during the second half of pregnancy and mediates important changes in the fetus to help it mature and prepare for birth and delivery [60]. PBDEs have been shown to disrupt thyroid function $[61,62]$, particularly by inhibiting thyroid hormone deiodinase activity $[63,64]$. Deiodinase activity in the placenta helps control levels of thyroid hormone in the fetus [65].

Our study has several important strengths. We measured several PFAS, including PFHxS, PFNA, Me-PFOSA$\mathrm{AcOH}$, that have not been as extensively studied as PFOA and PFOS. Our study population also included a racially/ 
Table 4 Adjusted linear regression coefficients and 95\% confidence intervals for the associations between tertiles of PFAS (ng/mL) and PBDE (ng/g lipid) concentrations > 80\% detection in maternal serum and gestational age in weeks and birth weight z-scores $(N=506)$

\begin{tabular}{|c|c|c|c|c|c|}
\hline & \multirow[b]{2}{*}{$\mathbf{N}$} & \multicolumn{2}{|c|}{ Gestational Age } & \multicolumn{2}{|c|}{ Birth Weight Z Score } \\
\hline & & $\beta$ & $95 \% \mathrm{Cl}$ & $\beta$ & $95 \% \mathrm{Cl}$ \\
\hline \multicolumn{6}{|l|}{ PFAS } \\
\hline \multicolumn{6}{|l|}{ PFOA } \\
\hline$<1.40$ & 167 & Reference & & Reference & \\
\hline $1.40-0.96$ & 172 & -0.29 & $(-0.74,0.17)$ & 0.13 & $(-0.10,0.35)$ \\
\hline$>0.96$ & 167 & -0.10 & $(-0.63,0.43)$ & 0.12 & $(-0.14,0.37)$ \\
\hline \multicolumn{6}{|l|}{ PFOS } \\
\hline$<1.40$ & 167 & Reference & & Reference & \\
\hline $1.40-2.56$ & 172 & -0.19 & $(-0.64,0.26)$ & -0.01 & $(-0.24,0.22)$ \\
\hline$>2.56$ & 167 & -0.08 & $(-0.59,0.43)$ & 0.02 & $(-0.23,0.27)$ \\
\hline \multicolumn{6}{|l|}{ PFHxS } \\
\hline$<0.24$ & 163 & Reference & & Reference & \\
\hline $0.24-0.49$ & 176 & 0.28 & $(-0.18,0.73)$ & 0.08 & $(-0.15,0.32)$ \\
\hline$>0.49$ & 167 & 0.09 & $(-0.47,0.65)$ & 0.15 & $(-0.12,0.42)$ \\
\hline \multicolumn{6}{|l|}{ PFNA } \\
\hline$<0.24$ & 171 & Reference & & Reference & \\
\hline $0.24-0.49$ & 244 & -0.28 & $(-0.71,0.14)$ & 0.01 & $(-0.20,0.23)$ \\
\hline$>0.49$ & 91 & -0.30 & $(-0.88,0.28)$ & -0.04 & $(-0.32,0.25)$ \\
\hline \multicolumn{6}{|c|}{ Me-PFOSA-AcOH } \\
\hline$<0.04$ & 165 & Reference & & Reference & \\
\hline $0.04-0.06$ & 171 & 0.12 & $(-0.32,0.57)$ & -0.24 & $(-0.46,-0.02)$ \\
\hline$>0.06$ & 170 & 0.18 & $(-0.27,0.63)$ & 0.09 & $(-0.14,0.32)$ \\
\hline \multicolumn{6}{|l|}{ Total PFAS } \\
\hline$<2.62$ & 169 & Reference & & Reference & \\
\hline $2.62-4.83$ & 171 & -0.34 & $(-0.80,0.12)$ & 0.01 & $(-0.22,0.24)$ \\
\hline$>4.83$ & 166 & -0.21 & $(-0.72,0.30)$ & 0.06 & $(-0.19,0.31)$ \\
\hline \multicolumn{6}{|l|}{ PBDE } \\
\hline \multicolumn{6}{|l|}{$\mathrm{BDE}-47$} \\
\hline$<8.47$ & 167 & Reference & & Reference & \\
\hline $8.47-14.22$ & 172 & -0.07 & $(-0.50,0.35)$ & -0.26 & $(-0.48,-0.04)$ \\
\hline$>14.22$ & 167 & -0.49 & $(-0.95,-0.02)$ & -0.14 & $(-0.37,0.09)$ \\
\hline \multicolumn{6}{|l|}{ BDE-99 } \\
\hline$<2.88$ & 169 & Reference & & Reference & \\
\hline $2.88-4.71$ & 170 & 0.07 & $(-0.35,0.49)$ & -0.25 & $(-0.47,-0.04)$ \\
\hline$>4.71$ & 167 & -0.25 & $(-0.71,0.22)$ & -0.08 & $(-0.31,0.15)$ \\
\hline \multicolumn{6}{|l|}{ Total PBDE } \\
\hline$<11.38$ & 171 & Reference & & Reference & \\
\hline 11.38-18.99 & 170 & -0.13 & $(-0.55,0.29)$ & -0.26 & $(-0.48,-0.04)$ \\
\hline$>18.99$ & 165 & -0.41 & $(-0.87,0.05)$ & -0.09 & $(-0.32,0.14)$ \\
\hline
\end{tabular}

Abbreviations: PFAS per- and polyfluoroalkyl substances, PBDE polybrominated diphenyl ethers, $C$ c confidence interval 
Table 5 Adjusted logistic regression coefficients and 95\% confidence intervals for the associations between tertiles of PFAS (ng/mL) and PBDE (ng/g lipid) concentrations > 80\% detection in maternal serum and preterm birth $(N=506)$

\begin{tabular}{|c|c|c|c|}
\hline & $\mathrm{N}(\mathrm{PTB}, \mathrm{FTB})$ & OR & $95 \% \mathrm{Cl}$ \\
\hline \multicolumn{4}{|l|}{ PFAS } \\
\hline \multicolumn{4}{|l|}{ PFOA } \\
\hline$<1.40$ & $(11,155)$ & Reference & \\
\hline $1.40-0.96$ & $(14,151)$ & 1.79 & $(0.75,4.28)$ \\
\hline$>0.96$ & $(16,146)$ & 2.37 & $(0.88,6.38)$ \\
\hline \multicolumn{4}{|l|}{ PFOS } \\
\hline$<1.40$ & $(13,153)$ & Reference & \\
\hline $1.40-2.56$ & $(13,155)$ & 1.21 & $(0.50,2.91)$ \\
\hline$>2.56$ & $(15,144)$ & 1.87 & $(0.72,4.88)$ \\
\hline \multicolumn{4}{|l|}{ PFHxS } \\
\hline$<0.24$ & $(13,148)$ & Reference & \\
\hline $0.24-0.49$ & $(17,157)$ & 1.32 & $(0.58,3.02)$ \\
\hline$>0.49$ & $(11,147)$ & 1.15 & $(0.38,3.41)$ \\
\hline \multicolumn{4}{|l|}{ PFNA } \\
\hline$<0.24$ & $(12,159)$ & Reference & \\
\hline $0.24-0.49$ & $(24,220)$ & 1.88 & $(0.83,4.30)$ \\
\hline$>0.49$ & $(9,82)$ & 2.06 & $(0.72,5.89)$ \\
\hline \multicolumn{4}{|c|}{ Me-PFOSA-AcOH } \\
\hline$<0.04$ & $(13,152)$ & Reference & \\
\hline $0.04-0.06$ & $(15,156)$ & 0.96 & $(0.40,2.28)$ \\
\hline$>0.06$ & $(18,152)$ & 1.14 & $(0.49,2.63)$ \\
\hline \multicolumn{4}{|l|}{ Total PFAS } \\
\hline$<2.62$ & $(12,157)$ & Reference & \\
\hline $2.62-4.83$ & $(17,154)$ & 1.70 & $(0.70,4.17)$ \\
\hline$>4.83$ & $(16,150)$ & 2.08 & $(0.74,5.82)$ \\
\hline \multicolumn{4}{|l|}{ PBDE } \\
\hline \multicolumn{4}{|l|}{$\mathrm{BDE}-47$} \\
\hline$<8.47$ & $(9,157)$ & Reference & \\
\hline $8.47-14.22$ & $(11,158)$ & 1.20 & $(0.47,3.06)$ \\
\hline$>14.22$ & $(21,137)$ & 2.35 & $(0.97,5.72)$ \\
\hline \multicolumn{4}{|l|}{ BDE-99 } \\
\hline$<2.88$ & $(13,156)$ & Reference & \\
\hline $2.88-4.71$ & $(11,159)$ & 0.78 & $(0.33,1.88)$ \\
\hline$>4.71$ & $(21,146)$ & 1.25 & $(0.55,2.84)$ \\
\hline \multicolumn{4}{|l|}{ Total PBDE } \\
\hline$<11.38$ & $(10,161)$ & Reference & \\
\hline 11.38-18.99 & $(13,157)$ & 1.21 & $(0.50,2.95)$ \\
\hline$>18.99$ & $(22,143)$ & 1.88 & $(0.79,4.48)$ \\
\hline
\end{tabular}

Abbreviations: PFAS per- and polyfluoroalkyl substances, PBDE polybrominated diphenyl ethers, $O R$ odds ratio, $\mathrm{Cl}$ confidence interval Models adjusted for maternal age, maternal race/ethnicity, pre-pregnancy BMI, maternal education, smoking status, parity, and food insecurity ethnically and socioeconomically diverse group of pregnant women. There is a need for more research among understudied minority populations that investigate how these groups may be disproportionately affected by environmental chemical exposures. Additionally, our study is larger than many previous studies examining the association between PBDEs and PFAS and birth outcomes. We also acknowledge several limitations of our study. Levels of some PBDEs and PFAS have been decreasing in the U.S. population over time and it is possible that the levels we measured in our study were at lower concentrations than the levels that would negatively impact birth outcomes. Our study may also have lacked adequate power to detect statistically significant effects. Furthermore, multiple tests were conducted and we cannot rule out the possibility of chance findings. Lastly, while we did adjust for many key covariates, residual confounding may still be a concern.

\section{Conclusions}

Among a diverse group of pregnant women in the San Francisco Bay Area, we found non-linear associations between prenatal exposure to PBDEs during the second trimester of pregnancy, birth weight z-scores, and gestational age. With the exception of Me-PFOSA-AcOH, we did not observe an association between increasing PFAS exposure and gestational age or birth weight $\mathrm{z}$-scores, although our results suggested that certain PFAS were slightly associated with PTB. Future studies should focus on emerging PFAS and PBDE congeners and substitutes, which are replacing those chemicals that are declining.

\section{Supplementary information}

Supplementary information accompanies this paper at https://doi.org/10. 1186/s12940-020-00654-2.

Additional file 1: Table S1. Demographic characteristics of Chemicals in Our Body $(\mathrm{ClOB})$ study population stratified by delivery hospital. Table S2. Crude linear regression coefficients and $95 \%$ confidence intervals for the associations between tertiles of PFAS ( $\mathrm{ng} / \mathrm{mL})$ and PBDE (ng/g lipid) concentrations in maternal serum and gestational age in weeks $(N=506)$. Table S3. Crude linear regression coefficients and 95\% confidence intervals for the associations between tertiles of PFAS $(\mathrm{ng} / \mathrm{mL})$ and PBDE ( $\mathrm{ng} / \mathrm{g}$ lipid) concentrations in maternal serum and birth weight $\mathrm{z}$-scores ( $N=506)$. Table S4. Crude odds ratios and 95\% confidence intervals for the associations between tertiles of PFAS ( $\mathrm{ng} / \mathrm{mL})$ and PBDE (ng/g lipid) concentrations in maternal serum and preterm birth $(N=506)$. Table S5. Linear regression coefficients and 95\% confidence intervals for the associations tertiles of wet weight PBDE $(\mathrm{ng} / \mathrm{mL})$ concentrations in maternal serum and gestational age in weeks $(N=506)$. Table S6. Linear regression coefficients and 95\% confidence intervals for the associations tertiles of wet weight PBDE (ng/mL) concentrations in maternal serum and birth weight z-scores $(N=506)$. Table $\mathbf{S 7}$. Linear regression coefficients and 95\% confidence intervals for the associations between tertiles of PFAS ( $\mathrm{ng} / \mathrm{mL}$ ) and PBDE (ng/g lipid) concentrations in maternal serum and birth weight (grams) among full term births $(N=461)$. Table S8. Linear regression coefficients and 95\% confidence intervals for the associations between tertiles of PFAS $(\mathrm{ng} / \mathrm{mL})$ and PBDE (ng/g lipid) concentrations in maternal serum and birth weight $z$-scores stratified by infant sex $(N=$ 
506). Table S9. Linear regression coefficients and 95\% confidence intervals for the associations between tertiles of PFAS ( $\mathrm{ng} / \mathrm{mL}$ ) and PBDE (ng/ $\mathrm{g}$ lipid) concentrations in maternal serum and gestational age stratified by infant $\operatorname{sex}(N=506)$.

\section{Abbreviations}

PFAS: Per- and polyfluoroalkyl substances; PBDE: Polybrominated diphenyl ethers; CA: California; CIOB: Chemicals in Our Bodies; BDE-47: 2,2',4,4'-tetrabromodiphenyl ether; BDE-99: 2,2',4,4',5-penta-bromodiphenyl ether; Cl: Confidence Interval; PTB: Preterm birth; LBW: Low birth weight; PFOA: Perfluorooctanoic Acid; PFOS: Perflucorooctane Sulfonic Acid: PFHxS: Perfluorohexanesulphonic Acid; PFNA: Perfluorononanoic Acid; BDE100: 2,2',4,4',6-penta-bromodiphenyl ether; BDE-153: 2,2',4,4',5,5'-hexabromodiphenyl ether; U.S.: United States; EPA: Environmental Protection Agency; ZSFG: Zuckerberg San Francisco General; MB: Mission Bay; ML: Moffitt Long; NH: Non-Hispanic; BMI: Body mass index; MDL: Method detection limit; Me-PFOSA-AcOH: Methyl-perfluorooctane sulfonamide Acetic Acid; mice: Multiple imputation via changed equations

\section{Acknowledgements}

We would like to thank our clinical research team for collecting the data, the study participants who participated in the CIOB study, and the DTSC biomonitoring team for the laboratory analysis of PBDEs and PFAS in serum.

\section{Authors' contributions}

SME was responsible for data cleaning and analysis, interpretation of results, writing-original draft, revisions and editing. EKHT was responsible for data cleaning and analysis, interpretation of results, writing-original draft, and editing. MAI was responsible for data cleaning and analysis, interpretation of results, writing-reviewing and editing. LC contributed to data analysis, interpretation of results, writing-reviewing and editing. YW was responsible for the measurement of 12 PFAS and 19 PBDEs in maternal serum. SCS was responsible for the measurement of 12 PFAS and 19 PBDEs in maternal serum. SG was responsible for the measurement of 12 PFAS and 19 PBDEs in maternal serum. JSP oversaw the PFAS and PBDEs method development and measurement analysis and was responsible for writing-reviewing and editing. AMP contributed to data analysis, interpretation of results, writing-reviewing and editing. ED was responsible for administration of research design, recruitment, and study protocol implementation, reviewing and editing. LV provided statistical advice on the data analysis. TJW was responsible for funding acquisition, project administration, reviewing and editing. RMF was responsible for funding acquisition, design of $\mathrm{CIOB}$ study protocols, oversight of statistical analysis, interpretation of results, project administration, writing original draft, revisions and editing. The authors read and approved the final manuscript.

\section{Funding}

This work was supported by grants RD83543301 from the United States Environmental Protection Agency, and P01ES022841 from the National Institute of Environmental Health Sciences, and UG3OD023272 and UH3OD023272 from the National Institutes of Health Environmental influences on Child Health Outcomes $(E C H O)$ program.

\section{Availability of data and materials}

Per University of California, San Francisco Institutional Review Board approval, the data that support the findings of this study are restricted for transmission to those outside the primary investigative team. Data sharing with investigators outside the team requires IRB approval. Requests may be submitted to the Program on Reproductive Health and the Environment (PRHE).

\section{Ethics approval and consent to participate}

Institutional Review Boards of the University of California, San Francisco (1000861) and Berkeley (2010-05-04).

\section{Consent for publication}

Not applicable.

\section{Competing interests}

The authors declare that they have no competing interests.

\section{Author details}

Trogram on Reproductive Health and the Environment, Department of Obstetrics, Gynecology and Reproductive Sciences, University of California, San Francisco, CA, USA. ${ }^{2}$ Department of Environmental Health Sciences, Fielding School of Public Health, University of California, Los Angeles, CA, USA. ${ }^{3}$ Environmental Chemistry Laboratory, Department of Toxic Substances Control, California Environmental Protection Agency, Berkeley, CA, USA. ${ }^{4}$ Department of Biostatistics, Mailman School of Public Health, Columbia University, New York, NY, USA. ${ }^{5}$ Department of Environmental Science, Policy and Management and School of Public Health, University of California, Berkeley, CA, USA.

Received: 17 July 2020 Accepted: 10 September 2020 Published online: 16 September 2020

\section{References}

1. U.S. Environmental Protection Agency. Technical Fact SheetPerfluorooctane sulfonate (PFOS) and perfluorooctanoic acid (PFOA). 2017.

2. U.S. Environmental Protection Agency. Technical Fact Sheet Polybrominated Diphenyl Ethers (PBDEs). 2017.

3. Mitro SD, Johnson T, Zota AR. Cumulative chemical exposures during pregnancy and early development. Curr Envir Health Rpt. 2015;2(4):367-78.

4. Geyer HJ, Schramm K-W, Darnerud PO, Aune M, Feicht A, Fried KW, et al. Terminal elimination half-lives of the brominated flame retardants TBBPA $\mathrm{HBCD}$, and lower brominated PBDEs in humans. Organohalogen Compd. 2004;66:6.

5. Olsen GW, Burris JM, Ehresman DJ, Froehlich JW, Seacat AM, Butenhoff JL, et al. Half-life of serum elimination of

perfluorooctanesulfonate,perfluorohexanesulfonate, and perfluorooctanoate in retired fluorochemical production workers. Environ Health Perspect. 2007; 115(9):1298-305.

6. Haukås M, Berger U, Hop H, Gulliksen B, Gabrielsen GW. Bioaccumulation of per- and polyfluorinated alkyl substances (PFAS) in selected species from the Barents Sea food web. Environ Pollut. 2007;148(1):360-71.

7. Midasch O, Drexler H, Hart N, Beckmann MW, Angerer J. Transplacental exposure of neonates to perfluorooctanesulfonate and perfluorooctanoate: a pilot study. Int Arch Occup Environ Health. 2007:80(7):643-8.

8. Kim S, Choi K, Ji K, Seo J, Kho Y, Park J, et al. Trans-placental transfer of thirteen perfluorinated compounds and relations with fetal thyroid hormones. Environ Sci Technol. 2011;45(17):7465-72.

9. Zhao Y, Ruan X, Li Y, Yan M, Qin Z. Polybrominated diphenyl ethers (PBDEs) in aborted human fetuses and placental transfer during the first trimester of pregnancy. Environ Sci Technol. 2013;47(11):5939-46.

10. Mazdai A, Dodder NG, Abernathy MP, Hites RA, Bigsby RM. Polybrominated diphenyl ethers in maternal and fetal blood samples. Environ Health Perspect. 2003:111(9):1249-52.

11. Johnson PI, Sutton P, Atchley DS, Koustas E, Lam J, Sen S, et al. The navigation guide-evidence-based medicine meets environmental health: systematic review of human evidence for PFOA effects on fetal growth. Environ Health Perspect. 2014;122(10):1028-39.

12. Meng Q, Inoue K, Ritz B, Olsen J, Liew Z. Prenatal exposure to Perfluoroalkyl substances and birth outcomes; an updated analysis from the Danish National Birth Cohort. IJERPH. 2018;15(9):1832.

13. Sagiv SK, Rifas-Shiman SL, Fleisch AF, Webster TF, Calafat AM, Ye X, et al. Early-pregnancy plasma concentrations of Perfluoroalkyl substances and birth outcomes in project viva: confounded by pregnancy hemodynamics? Am J Epidemiol. 2018;187(4):793-802.

14. Chen M-H, Ha E-H, Wen T-W, Su Y-N, Lien G-W, Chen C-Y, et al. Perfluorinated Compounds in Umbilical Cord Blood and Adverse Birth Outcomes. PLoS One. 2012;7(8):e42474-Meliker J, editor.

15. Maisonet M, Terrell ML, McGeehin MA, Christensen KY, Holmes A, Calafat AM, et al. Maternal concentrations of Polyfluoroalkyl compounds during pregnancy and fetal and postnatal growth in British girls. Environ Health Perspect. 2012;120(10):1432-7.

16. Manzano-Salgado CB, Casas M, Lopez-Espinosa M-J, Ballester F, Iñiguez C, Martinez D, et al. Prenatal exposure to perfluoroalkyl substances and birth outcomes in a Spanish birth cohort. Environ Int. 2017;108:278-84.

17. Apelberg BJ, Witter FR, Herbstman JB, Calafat AM, Halden RU, Needham LL et al. Cord serum concentrations of Perfluorooctane Sulfonate (PFOS) and Perfluorooctanoate (PFOA) in relation to weight and size at birth. Environ Health Perspect. 2007;115(11):1670-6. 
18. Zhao X, Peng S, Xiang Y, Yang Y, Li J, Shan Z, et al. Correlation between prenatal exposure to Polybrominated Diphenyl ethers (PBDEs) and infant birth outcomes: a meta-analysis and an experimental study. IJERPH. 2017; 14(3):268.

19. Chen L, Wang C, Cui C, Ding G, Zhou Y, Jin J, et al. Prenatal exposure to polybrominated diphenyl ethers and birth outcomes. Environ Pollut. 2015; 206:32-7.

20. Stasinska A, Heyworth J, Reid A, Callan A, Odland J $\varnothing$, Trong Duong P, et al. Polybrominated diphenyl ether (PBDE) concentrations in plasma of pregnant women from Western Australia. Sci Total Environ. 2014;493:554-61.

21. Harley KG, Chevrier J, Schall RA, Sjodin A, Bradman A, Eskenazi B. Association of Prenatal Exposure to Polybrominated Diphenyl ethers and infant birth weight. Am J Epidemiol. 2011;174(8):885-92.

22. Peltier MR, Koo H-C, Getahun D, Menon R. Does exposure to flame retardants increase the risk for preterm birth? J Reprod Immunol. 2015;107: 20-5.

23. U.S. Environmental Protection Agency O of CS and PP. Fact Sheet: 2010/ 2015 PFOA Stewardship Program [Internet]: US EPA; 2016. [cited 2019 Aug 3]. Available from: https://www.epa.gov/assessing-and-managing-chemicalsunder-tsca/fact-sheet-20102015-pfoa-stewardship-program.

24. U.S. Department of Health and Human Services, Public Health Service, Agency for Toxic Substances and Disease Registry. Toxicological Profile for Polybrominated Diphenyl Ethers (PBDEs) [Internet]. 2017 [cited 2019 Aug 20]. Available from: https://www.atsdr.cdc.gov/toxprofiles/tp.asp?id=901 $\&$ tid $=183$.

25. State of California D of CA Bureau of Electronic \& Appliance Repair, Home Furnishings \& Thermal Insulation. Technical Bulletin 117-2013, Requirements, Test Procedure and Apparatus for Testing the Smolder Resistance of Materials Used in Upholstered Furniture [Internet]. 2013 [cited 2019 Sep 1]. Available from: https://bhgs.dca.ca.gov/about_us/tb117_2013.pdf.

26. Standen A. It's Official: Toxic Flame Retardants No Longer Required in Furniture [Internet]: KQED; 2013. [cited 2019 Sep 1]. Available from: https://www.kqed.org/science/11318/its-official-toxic-flame-retardants-nolonger-required-in-furniture.

27. Zota AR, Rudel RA, Morello-Frosch RA, Brody JG. Elevated house dust and serum concentrations of PBDEs in California: unintended consequences of furniture flammability standards? Environ Sci Technol. 2008;42(21):8158-64.

28. Zota AR, Park J-S, Wang Y, Petreas M, Zoeller RT, Woodruff TJ. Polybrominated Diphenyl ethers, Hydroxylated Polybrominated Diphenyl ethers, and measures of thyroid function in second trimester pregnant women in California. Environ Sci Technol. 2011;45(18):7896-905.

29. U.S. Department of Health and Human Services, Centers for Disease Control and Prevention. Fourth National Report on Human Exposure to Environmental Chemicals, Updated Tables, January 2019, Volume 1 [Internet]. Atlanta; 2019. [cited 2019 Aug 3]. Available from: https://www.cdc. gov/exposurereport.

30. Olsen GW, Mair DC, Lange CC, Harrington LM, Church TR, Goldberg CL, et al. Per- and polyfluoroalkyl substances (PFAS) in American red Cross adult blood donors, 2000-2015. Environ Res. 2017:157:87-95.

31. Hurley S, Goldberg D, Wang M, Park J-S, Petreas M, Bernstein L, et al. Time Trends in Per- and Polyfluoroalkyl Substances (PFASs) in California Women: Declining Serum Levels, 2011-2015. Environ Sci Technol. 2018;52(1):277-87.

32. Kato $K$, Wong L-Y, Jia LT, Kuklenyik Z, Calafat AM. Trends in exposure to Polyfluoroalkyl Chemicals in the U.S. population: 1999-2008. Environ Sci Technol. 2011:45(19):8037-45.

33. Morello-Frosch R, Cushing $\sqcup$, Jesdale BM, Schwartz JM, Guo W, Guo T, et al. Environmental Chemicals in an Urban Population of pregnant women and their newborns from San Francisco. Environ Sci Technol. 2016:50(22):12464-72.

34. Parry E, Zota AR, Park J-S, Woodruff TJ. Polybrominated diphenyl ethers (PBDEs) and hydroxylated PBDE metabolites (OH-PBDEs): a six-year temporal trend in northern California pregnant women. Chemosphere. 2018:195:777-83.

35. Domingo JL, Nadal M. Per- and Polyfluoroalkyl substances (PFASs) in food and human dietary intake: a review of the recent scientific literature. J Agric Food Chem. 2017;65(3):533-43.

36. Trowbridge J, Gerona RR, Lin T, Rudel RA, Bessonneau V, Buren H, et al. Exposure to Perfluoroalkyl substances in a cohort of women firefighters and Office Workers in san Francisco. Environ Sci Technol. 2020:54(6):3363-74.

37. Carmichael SL, Yang W, Herring A, Abrams B, Shaw GM. Maternal food insecurity is associated with increased risk of certain birth defects. J Nutr. 2007;137(9):2087-92
38. Dolatian M, Sharifi N, Mahmoodi Z. Relationship of socioeconomic status, psychosocial factors, and food insecurity with preterm labor: a longitudinal study. Int J Reprod Biomed (Yazd). 2018;16(9):563-70.

39. Anderson SA, editor. Core Indicators of Nutritional State for Difficult-toSample Populations. J Nutr. 1990;120(suppl_11):1555-600.

40. Zota AR, Linderholm L, Park J-S, Petreas M, Guo T, Privalsky ML, et al. Temporal comparison of PBDEs, OH-PBDEs, PCBs, and OH-PCBs in the serum of second trimester pregnant women recruited from San Francisco general hospital, California. Environ Sci Technol. 2013;47(20):11776-84.

41. Impinen A, Longnecker MP, Nygaard UC, London SJ, Ferguson KK, Haug LS, et al. Maternal levels of perfluoroalkyl substances (PFASs) during pregnancy and childhood allergy and asthma related outcomes and infections in the Norwegian mother and child (MoBa) cohort. Environ Int. 2019;124:462-72.

42. Talge NM, Mudd LM, Sikorskii A, Basso O. United States birth weight reference corrected for implausible gestational age estimates. Pediatrics. 2014;133(5):844-53.

43. van Buuren S, Groothuis-Oudshoorn K. mice: Multivariate Imputation by Chained Equations in R. Journal of Statistical Software; 2011. 1, 3; 2011 Dec 12. Available from: https://www.jstatsoft.org/v045/i03.

44. Varshavsky JR, Sen S, Robinson JF, Smith SC, Frankenfield J, Wang Y, et al. Racial/ethnic and geographic differences in polybrominated diphenyl ether (PBDE) levels across maternal, placental, and fetal tissues during midgestation. Sci Rep. 2020;10(1):12247.

45. Starling AP, Adgate JL, Hamman RF, Kechris K, Calafat AM, Ye X, et al. Perfluoroalkyl substances during pregnancy and offspring weight and adiposity at birth: examining mediation by maternal fasting glucose in the healthy start study. Environ Health Perspect. 2017;125(6):067016.

46. Kato K, Wong L-Y, Chen A, Dunbar C, Webster GM, Lanphear BP, et al. Changes in serum concentrations of maternal poly- and perfluoroalkyl substances over the course of pregnancy and predictors of exposure in a multiethnic cohort of Cincinnati, Ohio pregnant women during 2003-2006. Environ Sci Technol. 2014;48(16):9600-8.

47. U.S. Environmental Protection Agency O of CS and PP. Risk Management for Per- and Polyfluoroalkyl Substances (PFASs) under TSCA [Internet].: US EPA; 2015. [cited 2019 Aug 30]. Available from: https://www.epa.gov/assessingand-managing-chemicals-under-tsca/risk-management-and-polyfluoroalkylsubstances-pfass.

48. Calafat AM, Wong L-Y, Kuklenyik Z, Reidy JA, Needham LL. Polyfluoroalkyl chemicals in the U.S. population: data from the National Health and nutrition examination survey (NHANES) 2003-2004 and comparisons with NHANES 1999-2000. Environ Health Perspect. 2007;115(11):1596-602.

49. Lucattini L, Poma G, Covaci A, de Boer J, Lamoree MH, Leonards PEG. A review of semi-volatile organic compounds (SVOCs) in the indoor environment: occurrence in consumer products, indoor air and dust. Chemosphere. 2018;201:466-82.

50. Scheringer $M$, Trier $X$, Cousins IT, de Voogt $P$, Fletcher $T$, Wang $Z$, et al. Helsingør statement on poly- and perfluorinated alkyl substances (PFASs). Chemosphere. 2014;114:337-9.

51. Kaijser M, Granath F, Jacobsen G, Cnattingius S, Ekbom A. Maternal pregnancy estriol levels in relation to anamnestic and fetal anthropometric data. Epidemiology. 2000;11(3):315-9.

52. Blazer S, Moreh-Waterman Y, Miller-Lotan R, Tamir A, Hochberg Z. Maternal hypothyroidism may affect fetal growth and neonatal thyroid function. Obstet Gynecol. 2003;102(2):232-41.

53. Benninghoff AD, Bisson WH, Koch DC, Ehresman DJ, Kolluri SK, Williams DE. Estrogen-like activity of perfluoroalkyl acids in vivo and interaction with human and rainbow trout estrogen receptors in vitro. Toxicol Sci. 2011; 120(1):42-58.

54. Henry ND, Fair PA. Comparison of in vitro cytotoxicity, estrogenicity and anti-estrogenicity of triclosan, perfluorooctane sulfonate and perfluorooctanoic acid. J Appl Toxicol. 2013;33(4):265-72.

55. Kjeldsen LS, Bonefeld-Jørgensen EC. Perfluorinated compounds affect the function of sex hormone receptors. Environ Sci Pollut Res Int. 2013;20(11): 8031-44.

56. Long M, Ghisari M, Bonefeld-Jørgensen EC. Effects of perfluoroalkyl acids on the function of the thyroid hormone and the aryl hydrocarbon receptor. Environ Sci Pollut Res Int. 2013;20(11):8045-56.

57. Ballesteros V, Costa O, Iñiguez C, Fletcher T, Ballester F, Lopez-Espinosa M-J. Exposure to perfluoroalkyl substances and thyroid function in pregnant women and children: a systematic review of epidemiologic studies. Environ Int. 2017:99:15-28. 
58. Eick SM, Ferguson KK, Milne GL, Rios-McConnell R, Vélez-Vega C, Rosario Z, et al. Repeated measures of urinary oxidative stress biomarkers and preterm birth in Puerto Rico. Free Radic Biol Med. 2020;146:299-305 2019/11/05 ed.

59. Costantini D, Blévin P, Herzke D, Moe B, Gabrielsen GW, Bustnes JO, et al. Higher plasma oxidative damage and lower plasma antioxidant defences in an Arctic seabird exposed to longer perfluoroalkyl acids. Environ Res. 2019; 168:278-85 2018/10/12 ed.

60. Forhead AJ, Fowden AL. Thyroid hormones in fetal growth and prepartum maturation. J Endocrinol. 2014;221(3):R87-103.

61. Zhou T, Taylor MM, DeVito MJ, Crofton KM. Developmental exposure to brominated diphenyl ethers results in thyroid hormone disruption. Toxicol Sci. 2002;66(1):105-16.

62. Fujimoto H, Woo G-H, Inoue K, Takahashi M, Hirose M, Nishikawa A, et al. Impaired oligodendroglial development by decabromodiphenyl ether in rat offspring after maternal exposure from mid-gestation through lactation. Reprod Toxicol. 2011;31(1):86-94

63. Butt CM, Wang D, Stapleton HM. Halogenated phenolic contaminants inhibit the in vitro activity of the thyroid-regulating deiodinases in human liver. Toxicol Sci. 2011;124(2):339-47.

64. Butt CM, Stapleton HM. Inhibition of thyroid hormone sulfotransferase activity by brominated flame retardants and halogenated phenolics. Chem Res Toxicol. 2013;26(11):1692-702.

65. Chan SY, Vasilopoulou E, Kilby MD. The role of the placenta in thyroid hormone delivery to the fetus. Nat Rev Endocrinol. 2009:5(1):45-54.

\section{Publisher's Note}

Springer Nature remains neutral with regard to jurisdictional claims in published maps and institutional affiliations.

Ready to submit your research? Choose BMC and benefit from:

- fast, convenient online submission

- thorough peer review by experienced researchers in your field

- rapid publication on acceptance

- support for research data, including large and complex data types

- gold Open Access which fosters wider collaboration and increased citations

- maximum visibility for your research: over $100 \mathrm{M}$ website views per year

At $\mathrm{BMC}$, research is always in progress.

Learn more biomedcentral.com/submissions 